\title{
Pain by mistake
}

Citation for published version (APA):

Traxler, J., von Leupoldt, A., \& Vlaeyen, J. W. S. (2022). Pain by mistake: investigating a link between error-related negativity and pain avoidance behavior. Pain, 163(2), E190-E201.

https://doi.org/10.1097/j.pain.0000000000002358

Document status and date:

Published: 01/02/2022

DOI:

10.1097/j.pain.0000000000002358

Document Version:

Publisher's PDF, also known as Version of record

Document license:
Taverne

Please check the document version of this publication:

- A submitted manuscript is the version of the article upon submission and before peer-review. There can be important differences between the submitted version and the official published version of record.

People interested in the research are advised to contact the author for the final version of the publication, or visit the DOI to the publisher's website.

- The final author version and the galley proof are versions of the publication after peer review.

- The final published version features the final layout of the paper including the volume, issue and page numbers.

Link to publication

\footnotetext{
General rights rights.

- You may freely distribute the URL identifying the publication in the public portal. please follow below link for the End User Agreement:

www.umlib.nl/taverne-license

Take down policy

If you believe that this document breaches copyright please contact us at:

repository@maastrichtuniversity.nl

providing details and we will investigate your claim.
}

Copyright and moral rights for the publications made accessible in the public portal are retained by the authors and/or other copyright owners and it is a condition of accessing publications that users recognise and abide by the legal requirements associated with these

- Users may download and print one copy of any publication from the public portal for the purpose of private study or research.

- You may not further distribute the material or use it for any profit-making activity or commercial gain

If the publication is distributed under the terms of Article $25 \mathrm{fa}$ of the Dutch Copyright Act, indicated by the "Taverne" license above, 


\title{
Pain by mistake: investigating a link between error- related negativity and pain avoidance behavior
}

\author{
Juliane Traxler ${ }^{a, b, *}$, Andreas von Leupoldt ${ }^{a}$, Johan W.S. Vlaeyen ${ }^{a, b}$
}

\begin{abstract}
Pain can be considered as a signal of "bodily error": errors put organisms at danger and activate behavioral defensive systems. If the error is of physical nature, pain is the warning signal that motivates protective action such as avoidance behavior to safeguard our body's integrity. Interestingly, an important component of neural error processing, the error-related negativity (ERN), has been found to be related to avoidance in anxiety disorders. The present study is the first to extend these findings to pain and investigate the relationship between ERN and pain-related avoidance behavior. It was hypothesized that individuals with larger ERN amplitudes would show more pain-related avoidance behavior and would be more persistent in their avoidance despite changes in the environment. Fifty-three healthy individuals performed the Eriksen flanker task during which their brain activity on correct and erroneous motor responses was recorded by means of high-density electroencephalography. Avoidance behavior was assessed with an arm reaching task using the HapticMaster robot arm. The results showed that, in contrast to our hypothesis, avoidance was not related to ERN amplitudes. Surprisingly, persons with elevated ERN amplitudes showed low levels of avoidance specifically during early acquisition trials. In contrast to earlier findings in anxiety disorders, individuals with elevated ERN amplitudes did not engage in more pain-related avoidance behavior. In fact, the opposite pattern was found at the start of acquisition: individuals with higher compared with lower ERN amplitudes were slower in learning to avoid pain. Replications and future studies on the relationship between ERN and avoidance behavior are needed.
\end{abstract}

Keywords: Pain, Fear avoidance, EEG, Error monitoring, Event-related potentials

\section{Introduction}

Avoidance behavior is a protective response to impending aversive events. During acute pain, avoidance of painful stimuli is adaptive and facilitates healing. However, avoidance becomes maladaptive when being disproportionate to the threat, when costs exceed benefits, or when generalizing to originally nonpainful actions. ${ }^{37}$ According to the fear-avoidance model of pain, ${ }^{64,65}$ pain-related avoidance is pivotal for development and maintenance of chronic pain. ${ }^{65}$ Individuals holding particularly negative pain beliefs and tending to misinterpret common pain episodes as signs of serious harm are more prone to avoid painful actions, rather than pursuing valued nonpain goals. The resulting disability $^{29,35,73}$ and negative affect can amplify pain experiences $^{34}$ and create a detrimental cycle of chronification. Despite the unequivocal importance of avoidance in pain chronicity, the underlying neural factors are still poorly understood. Enhanced knowledge of these neural mechanisms may help explain how excessive avoidance develops and why some persons are more prone to it than others.

\footnotetext{
Sponsorships or competing interests that may be relevant to content are disclosed at the end of this article.

a Research Group Health Psychology, KU Leuven, Leuven, Belgium, ${ }^{b}$ Experimental Health Psychology, Maastricht University, Maastricht, the Netherlands

${ }^{*}$ Corresponding author. Address: Department of Psychology and Educational Sciences, KU Leuven, Tiensestraat 102, Box 3726, 3000 Leuven, Belgium. Tel.: +32 163281 68. E-mail address: juliane.traxler@kuleuven.be (J. Traxler).

PAIN 00 (2021) 1-12

(C) 2021 International Association for the Study of Pain

http://dx.doi.org/10.1097/j.pain.0000000000002358
}

Several studies provided evidence for relationships between a neural correlate of error commission, the error-related negativity $(E R N)$, and the development of anxiety and obsessivecompulsive disorder in which avoidance also plays a key role. ${ }^{21,47,48}$ The ERN is an event-related potential measured with electroencephalography (EEG), which occurs $\sim 100 \mathrm{~ms}$ after error commission at fronto-central scalp positions. It originates in the anterior cingulate cortex, ${ }^{40}$ is considered to reflect sensitivity to threat, especially in unpredictable contexts, ${ }^{27}$ and is associated with mobilization of defensive motivational systems. ${ }^{20,24}$ Its application to pain remains untested but studies from related research fields suggest it to be highly promising: Firstly, chronic pain has many resemblances to sustained anxiety, which is associated with increased ERN amplitudes. ${ }^{69,74}$ Secondly, the ERN also relates to avoidance learning in healthy individuals $^{14,20,42}$ and, thirdly, it can be elicited through somatosensory feedback ${ }^{13,39}$ as would be the case in pain. Furthermore, the ERN could reflect prediction errors such as behavioral performance or sensory input being worse than expected. ${ }^{24,72}$ Following the predictive coding account, such prediction errors shape the perception of and behavioral responses to pain. ${ }^{45}$ Hence, pain may be conceptualized as "bodily error" that, because of its potential harmfulness, is highly salient and motivates defensive action, including avoidance behavior. It is conceivable that individuals being particularly sensitive to these types of errors, ie, perceiving pain as highly threatening, also show increased neural processing of errors in general as characterized by elevated ERN amplitudes.

This study first investigated whether ERN amplitudes are associated with pain avoidance behavior. Specifically, participants completed the Eriksen flanker task to elicit errors and an 
arm reaching task to assess pain-related avoidance. Furthermore, given that unpredictability increases the ERN and painrelated avoidance, ${ }^{2}$ learned avoidance responses turned ineffective for $50 \%$ of participants in a second phase. We expected participants with elevated ERN amplitudes to show more avoidance during pain challenges and to be more persistent therein in unpredictable contexts, especially when showing high fear of movement-related pain. Moreover, associations between ERN and individual differences potentially affecting avoidance were explored.

\section{Methods}

\subsection{Participants}

Based on an a priori sample size calculation using $\mathrm{G}^{*}$ Power $^{10,11}$ with the effect size obtained by Frank et al. ${ }^{14}$ using the correlation: bivariate normal model exact test, a number of 46 participants are needed to reach a power of $0.95(\alpha=0.05)$. Considering potential dropouts and nonresponders, the study aimed at including 60 participants in total. Participants were recruited at the University of Leuven, Belgium, using posters, flyers, word of mouth, and through an online platform for participant recruitment.

Participants were eligible for participation if they were aged between 18 and 55 years, right-handed, proficient in the Dutch language, and able to consent autonomously. Exclusion criteria comprised a self-reported (1) mental and/or neurological disorder, (2) cardiovascular disease, (3) acute and/or chronic pain (defined as pain on most days for 3 months or longer), (4) past operation at the right elbow (location of electrode placement), (5) pregnancy, (6) use of an electronic implant (eg, a pacemaker), (7) having been asked by one's doctor to avoid stressful situations, or (8) left-handedness, which were assessed with a respective self-report check list. Besides, participants were excluded post hoc when they committed less than 6 errors on the flanker task $^{44}$ or when they stopped either of the tasks prematurely.

Written informed consent was obtained from each participant before both testing sessions. At the end of the second session, participants received partial course credit or a monetary compensation $(8 € / h)$. The procedures conformed to the Helsinki Declaration and were approved by the institutional ethics committee (Social and Societal Ethics Committee; approval reference number: G-2017 11 994). The study was preregistered on the Open Science Framework (osf.io/u9b72/).

\subsection{Apparatus and stimulus material}

\subsubsection{Electroencephalography}

To measure event-related potentials in response to errors, an electroencephalogram was recorded continuously from the scalp with a 129-channel system (Philips Electrical Geodesics, Inc) using a sampling rate of $250 \mathrm{~Hz}$. The vertex sensor was used as reference electrode, and electrode impedances were kept below $50 \mathrm{k} \Omega$.

\subsubsection{HapticMaster}

The HapticMaster ( $\mathrm{HM})$ is a 3 degrees-of-freedom, admittancecontrolled and force-controlled robotic arm (FCS Robotics; Moog, Inc, East Aurora, New York). Similar to a joystick, the $\mathrm{HM}$ can be used to control virtual objects in a computer task on the screen in front of the participants. The device responds to the force and direction exerted on the handgrip with the according displacement, allowing for minimal friction and a natural feeling of motion. The HM records the exact positions in the trajectory over time, as well as exerted force and velocity during each movement. Visual feedback of all movements was provided through a 46inch LCD screen (36PFL3208K/12; Koninklijke Philips N.V., Amsterdam, the Netherlands). In the present experiment, the range of movement of the $\mathrm{HM}$ was confined to a 2-dimensional horizontal movement plane with a $1 \mathrm{~m}$ radius and a depth of $0.35 \mathrm{~m}$.

\subsubsection{Stimuli}

Electrocutaneous stimuli (hereafter referred to as "e-stim") of 2 milliseconds duration were used as the painful stimulation in the movement task. The e-stim was generated by a constant-current stimulator (DS7A; Digitimer, Welwyn Garden City, England) and delivered to the triceps tendon of the right arm through a reusable stainless steel bar electrode (MedCat, Klazienaveen, the Netherlands) filled with K-Y gel. The intensity of the e-stim was individually adjusted using a calibration procedure ${ }^{36}$ in which a series of e-stims of increasing intensity was applied. Participants were instructed to verbally rate each of these stimuli on a 0 to 10 numeric rating scale with 0 meaning "you felt nothing," 3 referring to a sensation that "starts to be painful but can easily be tolerated," and 10 being the "worst tolerable pain." As in previous studies, ${ }^{18,36}$ a stimulus that "is significantly painful and requires some effort to tolerate," which unbeknown to participants marked 8 on the scale, was targeted. The mean physical intensity chosen in this experiment was $24.42 \mathrm{~mA}(\mathrm{SD}=13.74$, range $=8-52)$, the mean rated stimulus intensity was $7.94(\mathrm{SD}=0.63$, range $=7-9)$ on the numeric rating scale. The same individual stimulus intensity was used throughout the experiment.

\subsubsection{Software}

In the first sessions, questionnaires were presented by means of Affect $4.0^{56}$ and the flanker task was presented in Affect 5.0, both of which were run on a Windows 7 Professional (Microsoft Corporation Redmond) 64-bit Dell OptiPlex 780 (Dell, Inc, Round Rock, TX) with 4-GB RAM, Duo CPU at 3.10 GHz.

For the second session, the HM experiment was programmed in $\mathrm{C}++$, using the Microsoft Integrated Development Environment Visual Studio (Microsoft Corporation Redmond, WA) as well as the development platforms OpenGL for graphical support and HM Application Programming Interface for controlling the HM. The HM task was run on a Windows 7 Professional (Microsoft Corporation Redmond) 64-bit Dell OptiPlex 9020 (Dell, Inc) with 16-GB RAM, CPU: 17-4770 at $3.4 \mathrm{GHz}$. Electrocutaneous stimulations were presented by means of Affect 4.0, ${ }^{56}$ which was run on a Windows XP Professional (Microsoft Corporation Redmond) 32-bit Dell OptiPlex 755 (Dell, Inc) with 2-GB RAM, Duo CPU at $2.33 \mathrm{GHz}$. TTL communication through PCI Express parallel ports was used to synchronize the 2 computers.

\subsection{Behavioral tasks}

\subsubsection{Flanker task}

To elicit errors, a well-established arrowhead version of the flanker task ${ }^{9,43,57}$ was used with 5 horizontally aligned white arrows presented on a black screen. For each trial, participants had to indicate the direction (ie, right or left) of the center arrow by respectively pressing the right or left mouse button while ignoring the 4 flanking arrows. A trial consisted of the presentation of the 
arrowheads (200 ms) followed by a blank screen until a response was given or the response window (1000 ms) had passed. The jittered intertrial interval varied randomly between 600 and 1000 $\mathrm{ms}$ with a mean of $800 \mathrm{~ms}$. Half of the trials were congruent with all arrows pointing into the same direction ( $<<<<<$ " or " >>>>>"), whereas the other half was incongruent with the middle arrow pointing in the opposite direction compared with the flanking arrows (" $<<><<$ " or " $>><>>$ "). These trials were presented in a pseudorandomized order, with no more than 3 subsequent presentations of the same stimulus, in 4 blocks of 60 trials each. Participants were instructed to make responses as correct and as fast as possible, with a response window of 200 to 1000 ms after stimulus offset. In between blocks, participants could take a break and resume the task when they were ready. When participants made errors on less than $10 \%$ of trials of a block $(<6)$, a message was displayed at the start of the break that encouraged participants to respond faster in the subsequent block.

\subsubsection{Robotic arm reaching task}

To assess avoidance behavior, a robotic arm reaching task using the HM based on a study by Meulders et al. ${ }^{36}$ was used. In this task, participants were requested to move a virtual ball from its starting location to a target location ("green arch") displayed on the screen in front of the participants (distance $=2 \mathrm{~m}$ ). Three different movement trajectories (T1-T3) were indicated by gray arches in the center of the movement plane. Different intensities of tractive force were applied by the $\mathrm{HM}$ for each of the trajectories, with a linear increase with lateral displacement: the straight trajectory $(\mathrm{T} 1)$ was free of tractive force, the moderate resistance was exerted on the middle trajectory (T2), and high resistance (max. $50 \mathrm{~N}$ ) was applied when the target location was reached using the rightmost trajectory (T3). In the present study, participants could always freely choose through which trajectory to reach the target location. Figure 1 provides the graphic illustrations of the experimental setup and Figure 2 displays the experimental and trial flows.

Visual and auditory signals were presented to indicate the start of each trial; trial completion was signaled with an auditory scoring signal, a prohibition sign, and the target arch lighting up in red. Participants were instructed to let go of the HM sensor on scoring because the device automatically repositioned to its starting location where it remained fixed for 3 seconds before the following trial started.

The tractive force exerted by the HM was kept constant across participants. Hence, to control for considerable interindividual variability in arm strength, which would influence the ease with which movements were performed, we measured the triceps extension force of participants' right arm by means of a handheld dynamometer (HHD microFET2; Hoggan Health Industries, Inc, Jordan, UT). This device registers the force that is exerted on its transducer in Newton (N). Participants sat on a chair with their core upright and stable and their feet placed firmly on the ground. They were instructed to hold their right arm in a $90^{\circ}$ angle, placing the ulnar side on the HHD, and extend it with maximal force 3 times, thus pressing against the HHD. Individual extensor muscle strength was operationalized as the average of these 3 measurements $(M=131.98 \mathrm{~N}, \mathrm{SD}=39.00$, range $=78.43$ 247.06).

In total, the task consisted of a total of 82 arm reaching movements divided into the following 3 phases:

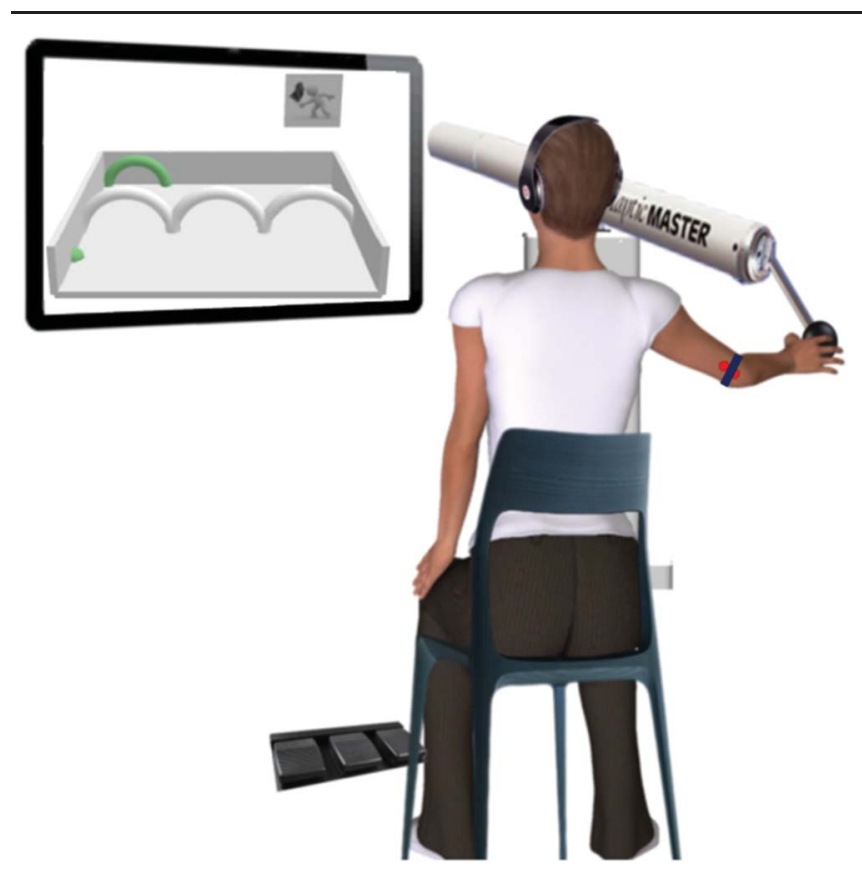

Figure 1. Experimental setup of the HapticMaster task with the participant seated in front of the LCD screen, the HapticMaster robot arm, and foot switch used to provide ratings of pain expectancy and fear of movement-related pain. Red dot and blue strap indicate electrode placement on the triceps tendon of the right arm for delivery of the e-stim (reprinted with permission from Meulders et al. $\left.{ }^{36}\right)$.

\subsubsection{Practice phase}

This phase consisted of 10 trials in which participants practiced operating the $\mathrm{HM}$ and were encouraged to explore all 3 movement trajectories under supervision of the experimenter. Participants were exposed to the tractive force, but no e-stims were applied. After the last trial, participants practiced operating the foot switch to provide pain expectancy and fear of movementrelated pain ratings.

\subsubsection{Acquisition phase}

In the 48-trial acquisition phase, e-stims were delivered to the right arm, which ensured spatio-temporal contiguity between the arm reaching movement and pain. The probability of e-stim presentation varied between the 3 trajectories: T1 was always paired with an e-stim (100\% reinforcement). When the target location was reached using $\mathrm{T} 2$, an e-stim was presented partially (50\% reinforcement). E-stims could be avoided altogether when using trajectory T3 (0\% reinforcement). E-stims were delivered approximately 6 ms after an arch was passed. In combination with the tractive force, a trade-off between pain avoidance and effort was created.

\subsubsection{Test phase}

The final phase consisted of 24 trials. At this point, participants were randomly assigned to one of 2 groups: a loss of predictability (LOP) group and a control group. Randomization was determined using the RAND function in Excel. For the control group, this phase was identical to the acquisition phase; for the LOP group, the reinforcement contingency changed such that e-stims were delivered after $30 \%$ of movements for each of the 3 trajectories, thus eliminating the option to avoid. 


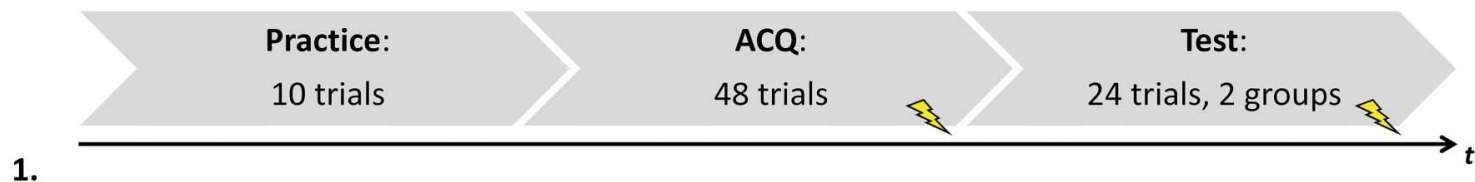

1.

\begin{abstract}
Start of a trial: the visual start signal is presented together with an auditory start signal, the "green ball" is positioned at the starting point in the lower left corner.
\end{abstract}

During arm reaching movement: the "green ball" is passed through one of the arches (here: through the first trajectory, T1). A painful electrocutaneous stimulus is administered on participants' right elbow according to the reinforcement schedule on the right.

End of trial: the "green ball" is passed through target location, which lights up red. The visual and auditory stop signals are presented and the HapticMaster repositions automatically to the starting point. A new trial starts after a 3 s interval.

Pain expectancy and pain-related fear ratings: After blocks of 18 trials, participants are asked to rate their pain-related fear and pain expectancy on a visual analogue scale displayed on the screen using the foot pedal.

2.

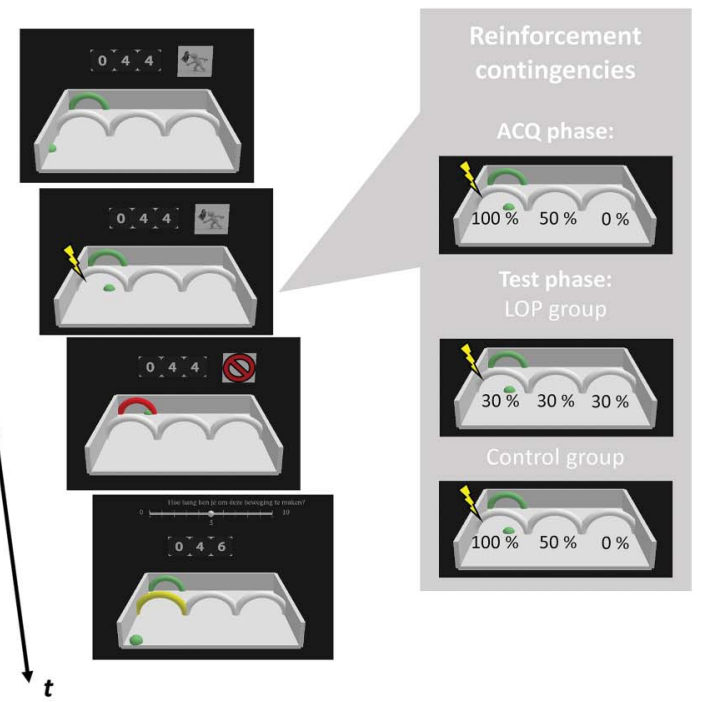

Figure 2. Schematic representation of the experimental and trial flows. Lightning bolts indicate the phases during which e-stim could be administered. For the test phase, participants were randomized into either the loss of predictability group (LOP) or the control group. Panel 1: The design of the experimental task. Panel 2: Illustration of the trial flow. Percentages refer to the reinforcement rates of the 3 arches. Note: Lightning bolts and reinforcement rates were added for clarification and were not visible to participants. ACQ, acquisition phase.

\subsection{Measures and outcomes}

\subsubsection{Behavioral avoidance}

Avoidance behavior was operationalized as the maximal deviation from the short trajectory that was paired with a painful estim (T1; for detailed description refer to Procedure section) on the $\mathrm{HM}$ task. This deviation is automatically logged by the HM in millimeter. In addition, and as an alternative measure of avoidance, we inspected the frequency with which the third trajectory was chosen in explorative analyses. These measures were taken during both acquisition (acquisition of avoidance) and test phase (persistence of avoidance).

\subsubsection{Error-related negativity}

The ERN was recorded using EEG during performance of the flanker task. Data were processed offline using Brain Electrical Source Analysis Research 6.0 (BESA GmbH, Gräfelfing, Germany). Data were filtered between 0.1 and $30 \mathrm{~Hz}$ and a $50 \mathrm{~Hz}$ notch filter was added. Ocular artifacts were corrected by means of the BESA algorithm, and noisy electrodes were interpolated or excluded on visual inspection with a maximum of $10 \%$ of the total number of electrodes. ${ }^{30}$ Response-locked epochs of 1500 ms (500 ms preresponse and $1000 \mathrm{~ms}$ postresponse) were extracted and averaged across the 4 blocks. As in previous studies, ${ }^{27,57,59}$ the 500 to $300 \mathrm{~ms}$ preresponse interval was used as the baseline. Trials with response times below $200 \mathrm{~ms}$ or above $1000 \mathrm{~ms}$ were excluded. ${ }^{68}$ Finally, data were rereferenced to the average reference.

The ERN was operationalized as the mean amplitude in a time window from 0 to $100 \mathrm{~ms}^{6,49,50}$ after the error response at frontocentral sites around $\mathrm{FCz}$ (Geodesic net electrode 6). In addition, the correct response negativity (CRN), which is a comparable albeit smaller negative deflection in the EEG signal than the ERN, that occurs after correct responses in the flanker task in the same time window (0-100 ms postresponse) at fronto-central sites was analyzed. The CRN was computed in the same way as the ERN, and the difference score between ERN and CRN $(\triangle E R N=$ ERN - CRN), which has been suggested to be more reliable than the ERN alone, ${ }^{49}$ was calculated as an additional read-out for the ERN.

\subsubsection{Questionnaires}

The following questionnaires were used to describe the sample and to explore additional potential relationships between the ERN and personality traits.

The Positive and Negative Affect Schedule-Trait version is a selfreport measure assessing positive and negative affect. ${ }^{66}$ Participants indicate on a 5-point Likert scale $(1=$ not at all and $5=$ very much) to which extent 20 different emotional states (eg, interested, upset, or alert) are generally applicable to them. The psychometric properties of the 2 subscales have been found to be good, including good convergent and discriminant validity. ${ }^{4}$ In the present sample, internal consistency for both the positive affect subscale $(\alpha=0.85)$ and the negative affect subscale $(\alpha=0.84)$ was high.

The State-Trait Anxiety Inventory-Trait version assesses trait anxiety by means of 20 items (eg, "I am tense" or "I am worried") that are rated on a 4-point Likert scale with the anchors 1 = "almost never" and 4 = "almost always." 55 The scale is reported to have a high internal consistency ranging between 0.86 and 0.95 , and the test-retest reliability between 0.65 and $0.75 .^{54}$ Its internal consistency in the present sample was high $(\alpha=0.87)$.

The Pain Catastrophizing Scale is a 13-item questionnaire that measures catastrophic thoughts and feelings about pain. ${ }^{58}$ Participants rate on a 5 -point Likert scale $(0-$ not at all and $4=$ always) to what extend statements, such as "I keep thinking about 
how much it hurts," apply to them with higher scores reflecting more catastrophic thinking. The scale has good psychometric properties, ${ }^{32}$ and its internal consistency in the present study was high ( $\alpha=0.88)$.

The Life Orientation Test-Revised assesses optimism and comprises 3 positive and 3 negative statements (eg, "I'm always optimistic about my future") and 4 filler items. ${ }^{51}$ The items are rated on a 5-point Likert scale ranging from $1=$ "strongly disagree" to $5=$ "strongly agree." Psychometric properties of this scale are satisfactory, ${ }^{17}$ although its internal consistency was rather low $(\alpha=0.59)$ in the present sample.

The Intolerance of Uncertainty Scale comprises 27 items that measure reactions to uncertainty and ambiguous situations. ${ }^{5,15}$ Participants indicate to which degree each statement (eg, "When I am uncertain, I can't go forward") applies to them on a 5-point Likert scale with the anchors $1=$ "not at all characteristic of me" to $5=$ "entirely characteristic of me." Helsen et al. ${ }^{23}$ reported excellent psychometric properties for this scale. In the present study, its internal consistency was high ( $\alpha=0.87$ ).

\subsection{Manipulation checks}

\subsubsection{Fear of movement-related pain and pain expectancy}

Ratings of fear of movement-related pain and pain expectancy were acquired 4 times during the HM movement task, after blocks of 18 trials, respectively. Pain expectancy was assessed with the question "To what degree do you expect an electrocutaneous stimulus when moving through this [the yellow] arch?" Fear of movement-related pain was assessed with the question "How afraid are you to perform this movement?" for each of the 3 movement trajectories separately. Answers were given on a visual analogue scale with the anchors $0=$ "not at all" to $10=$ "very much" by means of a foot pedal. Both questions were posed for each of the 3 trajectories (ie, 6 questions per block) and were shown at the top of the screen, the respective arch lit up yellow. The visual analogue scale appeared underneath the question; a rating could be given by means of a Windows 7 compatible foot switch with 3 pedals (USB-3FS-2; Scythe, Tokyo, Japan), which allowed for minimal interference with the arm reaching task. Participants could scroll left and right by pressing the left and middle foot pedals, respectively, and confirm their selection by pressing the right pedal.

\subsubsection{Skin conductance}

The skin conductance level (SCL) was measured throughout the experiment as an additional explorative marker of physiological arousal using the Coulbourn LabLinc $V$ system (Coulbourn Instruments, Whitehall, PA) and a National Instruments data acquisition card (National Instruments Corp, Austin, TX). A $0.5 \mathrm{~V}$ current was passed between 2 electrodes $(11 \mathrm{~mm}$, disposable, pregelled with isotonic gel [Biopac Systems, Inc, Goleta, CA]) attached to the hypothenar eminence of the left hand. The interelectrode distance was approximately $24 \mathrm{~mm}$. The sampling rate used was $1000 \mathrm{~Hz}$.

\subsubsection{Postexperimental questionnaire and blinding checks}

At the end of the experiment, participants answered a series of questions relating to (1) whether they were aware of the study goal ("What do you think was this study about?") or (2) the contingencies between movement trajectories and e-stim presentation ("Did you think that some of the arches were followed by an electrocutaneous stimulus more often than others? If so, please specify.") and (3) whether they tried to avoid the e-stim ("Did you try to avoid the stimuli?"). (4) We also assessed whether participants experienced a contingency change during the task ("Did you think that the rules according to which a stimulus was administered changed at some point?"). Finally, participants rated 3 questions on visual analogue scales ranging from 0 ("none/not at all") to 10 ("very much/the worst pain imaginable"): (1) how much effort they had to put up against the tractive force ("How much effort did the resistance cost you?"), (2) to which degree they desired to avoid the e-stim ("To which degree did you want to avoid the electrocutaneous stimulus?"), and (3) the intensity of the e-stim ("How intense was the electrocutaneous stimulus?").

\subsection{Procedure}

The experiment consisted of a 2-day protocol with on average 2.7 days $(\mathrm{SD}=4.35)$ in between the 2 sessions. In the first session, the ERN was assessed using EEG measurements, whereas in the second session, pain avoidance behavior was measured by means of the HM arm reaching task. On arrival in the laboratory, participants were informed about the general procedure of the experiment and the specific tasks of the respective session. This included information about the voluntary character of the study and the delivery of painful stimulation in the second session. After checking eligibility for participation, participants were asked to provide their informed consent.

At the start of the first session, participants filled in the questionnaires. Next, the EEG net was attached and participants were seated approximately $60 \mathrm{~cm}$ in front of a computer screen and underwent a practice phase of the flanker task before the actual experimental phase started. Finally, participants were thanked and practical information for the second session was provided.

In the second session, participants' extensor muscle strength was measured, and the electrodes for e-stim delivery and for SCL measurement were attached. Afterwards, participants were seated on a chair in front of the HM with the handgrip of the robotic arm positioned approximately $10 \mathrm{~cm}$ in front of the participant's right shoulder. The e-stim was calibrated and both written and verbal instructions for the HM task were given. On completion of the HM task and filling in the postexperimental questionnaire as blinding check, participants were debriefed and thanked for their participation.

\subsection{Statistical analyses}

Statistical analyses were performed using SPSS $25 .{ }^{25}$ Descriptive statistics were retrieved for participant characteristics, questionnaire data, blinding, and contingency awareness data, and assumptions were checked for linear regression analysis. Flanker task performance was assessed based on error rate, reaction times, and posterror slowing. Posterror slowing was calculated as the average difference in reaction times between pre-error and associated posterror trials, ${ }^{7}$ including only those error trials that were preceded by a correct trial. A series of repeated measures (RMs) analyses of variance (ANOVAs) were performed to test acquisition and persistence of avoidance behavior, pain expectancy, and fear of movement-related pain. These analyses were repeated controlling for arm strength, perceived and actual intensity of the e-stim, as well as for effort and desire to avoid. Moreover, a RM ANOVA of skin conductance across acquisition and test phase was conducted. 
To test the main hypothesis, multiple regression analyses were performed on amplitudes of ERN, CRN, and $\triangle E R N$ as predictors and avoidance behavior (mean maximal deviation) during acquisition and test phase as outcome. In addition, learning curves may differ between individuals, although all participants had successfully acquired avoidance by the end of the acquisition phase. Therefore, we decided to explore potential differences in the learning process and how these are associated with our variables of interest: The first (early) and last (late) 10 acquisition trials were investigated separately by means of exploratory regression analyses performed on ERN, CRN, and $\Delta E R N$. To test whether the ERN predicts persistence of avoidance behavior, a linear regression analysis with ERN as predictor and number of avoidance trials (T3) during the test phase as outcome was conducted among the LOP group alone, as the control group did not undergo the LOP manipulation that we consider crucial to address this specific research question. Instead, inclusion of the control group allowed us to exclude potential alternative explanations for any observed changes in avoidance behavior, such as participants getting tired or bored towards the end of the session, and instead attribute these changes to the LOP manipulation. Furthermore, exploratory correlation analyses of ERN and $\triangle E R N$ with individual difference measures were conducted.

The significance level was set at $P<0.05$. GreenhouseGeisser and Pillai Trace corrections are reported when appropriate. Pairwise comparisons were used to further analyze the data, using Holm-Bonferroni corrections to correct for multiple testing. Uncorrected degrees of freedom, corrected $P$ values, and the effect size partial eta-squared $\left(\eta_{p}^{2}\right)$ are reported.

\section{Results}

\subsection{Sample characteristics}

A total of 64 participants took part in the study. Four participants were excluded because of technical problems during testing and 7 participants were excluded because less than 6 errors remained after data preprocessing. ${ }^{44}$ Consequently, the analyses were conducted on the final sample of 53 participants (11 males) aged 18 to 41 years $(M=19.04, S D=3.29)$. Participant characteristics of the whole sample and the 2 groups separately are described in Table 1.

\subsection{Blinding, contingency awareness, and exit questions}

On completion of the experiment, none of the participants was fully aware of the study goal, although 33 (62.2\%) were partially aware. They reported that the second session was about the influence of painful stimulation on movement choices or avoidance behavior. Almost all participants (51 of the 53; $96.2 \%)$ were contingency aware, and noticed a relationship between movement trajectory and e-stim presentation. In the test group, 28 of the 29 participants (96.6\%) were aware of the contingency change between acquisition phase and test phase.

In the postexperimental questionnaire, participants reported that they exerted a mean effort of $4.02(S D=1.79$, range $=1-8)$ against the tractive force. Retrospective e-stim intensity ratings indicated that the stimuli continued to be experienced as painful $(\mathrm{M}=7.07, \mathrm{SD}=0.99$, range $=5-9)$ in all cases except one individual who rated the e-stim intensity as $0(=$ no sensation at all), possibly indicating a misunderstanding of the question. Fortyeight participants (90.6\%) reported that they tried to avoid the stimulus, whereas 5 did not. Desire to avoid was rated as relatively high $(M=7.00, S D=2.06$, range $=2-10)$.

\subsection{Flanker task performance}

On average participants committed 17.57 errors (SD $=14.00$; range $=6-91 ; 8.9 \%$ of all accepted responses) on the flanker task and gave 186.06 correct responses $(\mathrm{SD}=34.09$; range $=70$ 231). Reaction times were significantly faster during error trials ( $M$ $=375.41 \mathrm{~ms}, \mathrm{SD}=105.20)$ compared with correct trials $\{\mathrm{M}=$ $462.06 \mathrm{~ms}, \mathrm{SD}=108.14 ; t(12,626)=26.34, P<0.001 ; 95 \%$ confidence interval $(\mathrm{Cl})[80.20-93.10]\}$. This is comparable to flanker task performances observed in other studies in healthy samples. ${ }^{41,44}$ The difference in reaction times between posterror trials $(\mathrm{M}=351.1 \mathrm{~ms}, \mathrm{SD}=125.01)$ and the associated pre-error trials $(\mathrm{M}=332.3 \mathrm{~ms}, \mathrm{SD}=118.45)$ was significant $(t(12,474)=$ 5.66, $P<0.001 ; 95 \% \mathrm{Cl}[1.23-2.54])$, indicating the commonly observed posterror slowing. 7,46

\subsection{Behavioral avoidance}

The $2 \times 3$ (Group [LOP vs control] $\times$ Phase [early acquisition, late acquisition, and test phase]) RM ANOVA on the mean maximal deviation from the straight trajectory (Fig. 3) revealed significant main effects of both Group, $F(1,51)=11.34, P=$ $0.001, \eta_{p}^{2}=0.18$, and Phase, $\mathrm{F}(2,50)=38.43, P<0.001, \eta_{p}^{2}$ $=0.61$. These were accommodated by a significant Group $\times$ Phase interaction effect, $F(2,50)=18.30, P<0.001, \eta_{p}^{2}=$ 0.42 . Pairwise comparisons showed that participants engaged in avoidance behavior significantly more often during late acquisition ( $\mathrm{M}=0.71, \mathrm{SD}=0.47)$ compared with early acquisition $(\mathrm{M}=0.19, \mathrm{SD}=0.43 ; P<0.001$; $95 \% \mathrm{Cl}[0.35$ $0.70])$ as well as test phase $(\mathrm{M}=0.30, \mathrm{SD}=0.58 ; P<0.001$;

Table 1

Means and standard deviations of the questionnaires for the whole sample $(n=53)$ and the 2 groups separately.

\begin{tabular}{lllll}
\hline & Mean (SD) & Range (min-max) & LOP group (n= 29) & Control group (n= 24) \\
\hline PA & $32.81(5.196)$ & $19-44$ & $33.31(4.706)$ & $32.21(5.778)$ \\
\hline STAI-T & $17.91(5.332)$ & $10-31$ & $17.93(5.063)$ & $17.88(5.751)$ \\
\hline PCS & $40.60(7.791)$ & $26-57$ & $39.69(7.978)$ & $41.71(7.578)$ \\
\hline LOT-R & $16.36(7.507)$ & $2-32$ & $15.93(7.573)$ & $16.88(7.555)$ \\
\hline IUS $^{*}$ & $20.85(2.938)$ & $15-27$ & $20.93(2.853)$ & $20.75(3.096)$ \\
\hline
\end{tabular}

* Full sample: $n=47$; Loss of predictability group: $n=24$; Control group: $n=23$; questionnaire data missing for 6 participants because of a technical error.

IUS, Intolerance of Uncertainty Scale; LOP, Ioss of predictability; LOT-R, Life Orientation Test-Revised; NA, Positive and Negative Affect Schedule-Trait negative affect; PA, Positive and Negative Affect Schedule-Trait positive affect; PCS, Pain Catastrophizing Scale; STAI-T, trait version of the State-Trait Anxiety Inventory. 
95\% Cl [0.22-0.53]); the latter of which, however, was driven by the interaction effect. Although there was no significant difference in avoidance behavior between the 2 groups during early or late acquisition $(F(2,50)=0.07, P=0.936)$, in the test phase the LOP group engaged in significantly less avoidance behavior compared with the control group $(F(1,52)=48.06, P$ $<0.001)$. When controlling for arm strength, perceived and actual intensity of the e-stim, effort and desire to avoid, these effects remained significant.

\subsection{Manipulation checks}

\subsubsection{Pain expectancy and fear of movement-related pain}

Two separate $2 \times 3 \times 3$ (Group [LOP vs control] $\times$ Trajectory [1, 2, and 3] $\times$ Phase [early acquisition, late acquisition, and test phase]) RM ANOVAs were conducted for ratings of pain expectancy and fear of movement-related pain.

The analysis on expectancy ratings (Fig. 4) revealed a significant main effect of Trajectory, $F(2,50)=281.57, P<$ $0.001, \eta_{p}^{2}=0.92$, but not of Phase, $F(2,50)=3.09, P=0.054, \eta_{p}^{2}$ $=0.18$, or Group, $\mathrm{F}(1,51)=1.98, P=0.165, \eta_{p}^{2}=0.04$. The Group $\times$ Trajectory $\times$ Phase interaction effect was significant, $F(4,48)=5.33, P=0.001, \eta_{p}^{2}=0.31$, suggesting a different development of pain expectancy for the 3 trajectories across phases between the 2 groups. Planned contrasts indicated that the differences in expectancy ratings between $\mathrm{T} 1$ and $\mathrm{T} 2(P=$ $0.009)$ as well as between T1 and T3 $(P<0.001)$ were larger in the control group compared with the LOP group. In the LOP group, the difference in expectancy ratings for $\mathrm{T} 1$ and $\mathrm{T} 3$ decreased from early acquisition to test phase in contrast to the control group that showed a rather stable T1 to T3 difference score across all phases $(P=0.006)$.

Regarding fear of movement-related pain ratings, all 3 main effects of Phase, $F(2,50)=5.56, P=0.007, \eta_{p}^{2}=0.18$, Trajectory, $F(2,50)=122.46, P<0.001, \eta_{p}^{2}=0.83$, and Group, $\mathrm{F}(1,51)=15.82, P=0.008, \eta_{p}^{2}=0.13$, were significant. Paralleling the results of expectancy ratings, the Group $\times$ Trajectory $\times$ Phase interaction effect on fear of movementrelated pain ratings (Fig. 5) was also significant, $F(4,48)=6.17, P$ $<0.001, \eta_{p}^{2}=0.34$. Planned contrasts showed that the differences in fear of movement-related pain ratings between T1 and T3 $(P=0.028)$ were larger in the control group compared with the LOP group.

\subsubsection{Skin conductance level}

In addition, we conducted an exploratory $2 \times 3$ (Group [LOP vs control] $\times$ Phase [early acquisition, late acquisition, and test phase]) RM ANOVA on SCL. The main effect of Phase was significant, $F(2,50)=5.01, P=0.01, \eta_{p}^{2}=0.17$. Pairwise comparisons revealed a significant increase $(P=0.013)$ in SCL from early acquisition ( $M=19.52 \mu \mathrm{S}, \mathrm{SD}=9.88)$ to test phase $(\mathrm{M}$ $=20.43 \mu \mathrm{S}, \mathrm{SD}=9.58)$. Neither the main effect of Group, F(2,50) $=0.74, P=0.393, \eta_{p}^{2}=0.01$, nor the interaction effect between Group and Phase, $F(2,50)=0.80, P=0.455, \eta_{p}^{2}=0.03$, was significant.

\subsection{Main analysis: error-related negativity and behavioral avoidance}

Figure 6 presents response-locked event-related potentials for error and correct responses on the flanker task. Simple linear regressions were performed to predict avoidance behavior during acquisition and test phase, respectively, based on participants' ERN amplitudes. The latter was conducted on the LOP group alone. Preliminary analyses ascertained that assumptions of normality and linearity were not violated. Nonsignificant effects were found both for the acquisition phase $(\beta=0.005 ; F(1,51)=3.69, P=0.06)$ with an $R^{2}$ of 0.067 and the test phase $(\beta=-0.003 ; F(1,27)=$ $0.47, P=0.501)$ with an $R^{2}$ of 0.017 . These results did not change notably when using the alternative avoidance measure (frequency of movements through T3; acquisition phase: $\beta=1.378 ; F(1,51)=3.384, P=0.072, R^{2}=0.062$; test

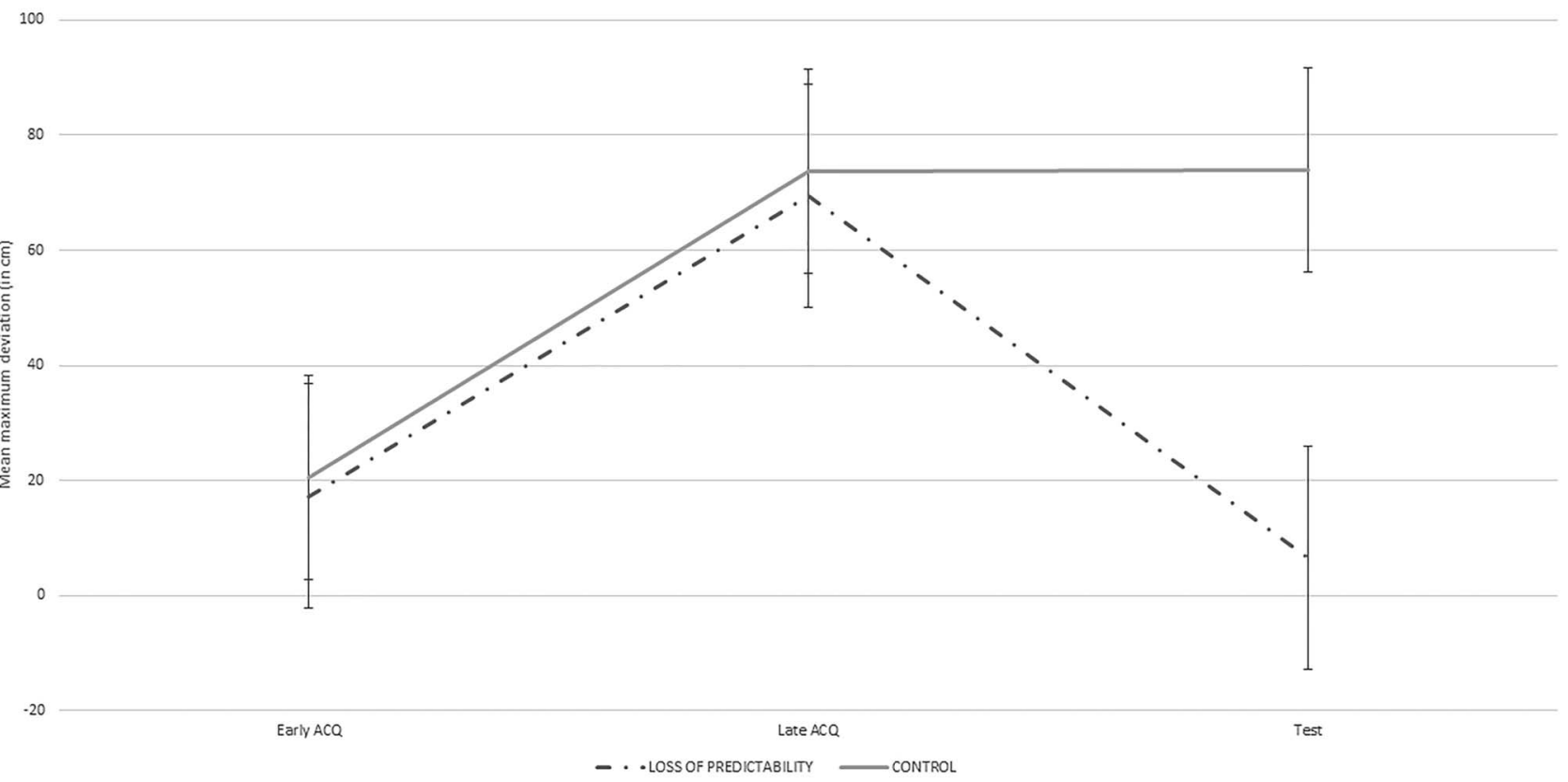

Figure 3. Mean maximal deviation from the shortest trajectory $(\mathrm{T} 1)$ for the loss of predictability group and the control group across time. Error bars represent SEM. $A C Q$, acquisition phase. 


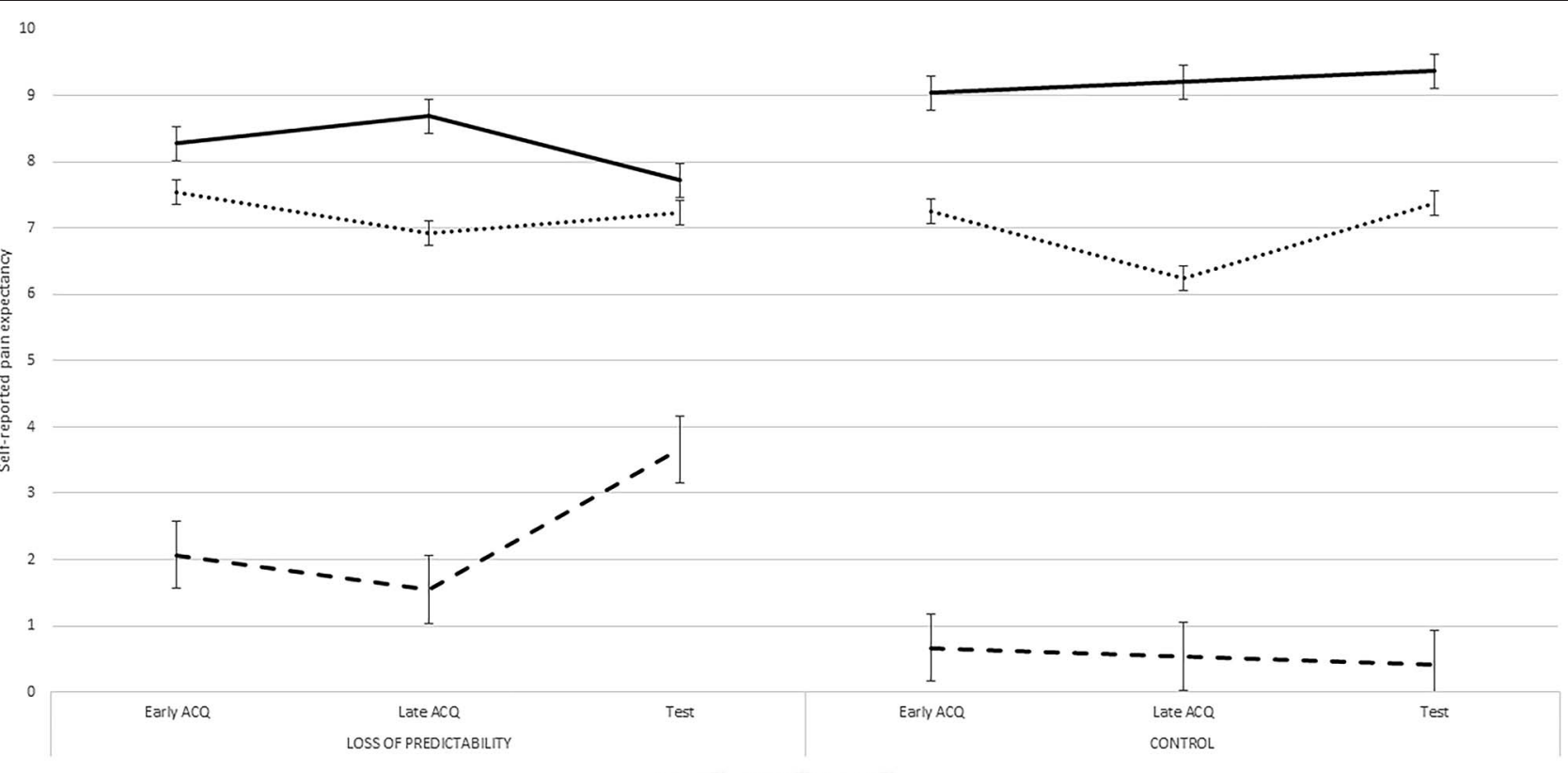

Figure 4. Expectancy ratings for the 3 different trajectories (T1-T3) in the loss of predictability and control groups during acquisition (ACQ) and test phase. Error bars represent SEM.

phase: $\left.\beta=-0.023 ; \mathrm{F}(1,27)=0.003, P=0.959, R^{2}=0.00\right)$. When adding $C R N$ and $\triangle E R N$ as predictors in an exploratory step, multiple linear regression analyses again revealed overall nonsignificant effects during acquisition $(F(2,50)=2.09, P=$ $0.134 ; R^{2}=0.077 ; \Delta$ ERN excluded $)$ and test phase $(F(2,26)=$ $0.26, P=0.777 ; R^{2}=0.019 ; \Delta$ ERN excluded). It was found that ERN was a significant predictor of avoidance behavior in acquisition $(\beta=0.007, P=0.050)$, whereas $C R N$ was not $(\beta=$ $-0.004, P=0.469)$. In the test phase, both ERN and CRN failed to significantly predict avoidance behavior $\left(\beta_{\mathrm{ERN}}=-\right.$ $\left.0.002, P=0.592 ; \beta_{\mathrm{CRN}}=-0.002, P=0.805\right)$.

\subsection{Exploratory analyses}

\subsubsection{Error-related negativity and acquisition of avoidance}

To examine whether ERN amplitudes are related to avoidance learning trajectories or whether a weak association between ERN and avoidance could be masked by a ceiling effect, a simple linear regression with ERN as predictor and avoidance behavior as outcome during early and late acquisition was conducted. A significant effect was found for early acquisition ( $\beta=0.007$; $\left.F(1,51)=4.69, P=0.035 ; R^{2}=0.084\right)$, but not for late acquisition $\left(\beta=0.005 ; \mathrm{F}(1,51)=2.33, P=0.133 ; R^{2}=0.044\right)$.



Figure 5. Pain-related fear ratings for the 3 different trajectories (T1-T3) in the loss of predictability and control groups during acquisition (ACQ) and test phase. Error bars represent SEM. 


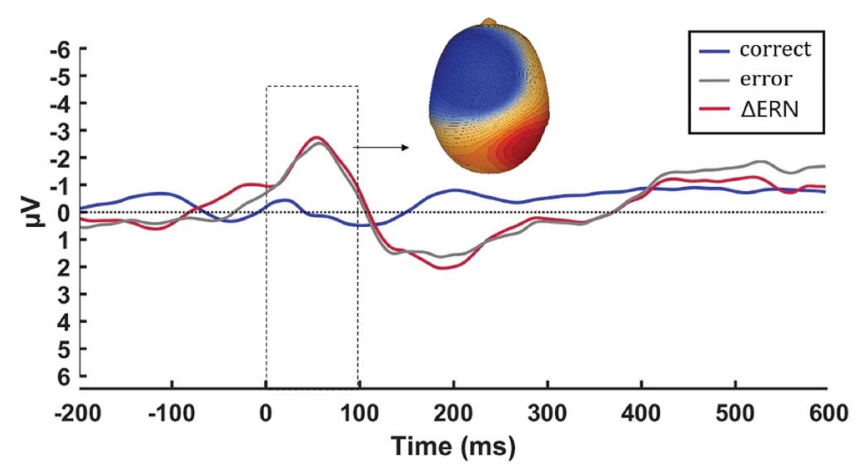

Figure 6. Response-locked grand average waveforms for the error-related negativity (ERN) and the correct response negativity (CRN) at FCz (Geodesic sensor E6) for incorrect and correct responses in the flanker task, respectively, as well as their difference score $(\Delta \mathrm{ERN})$. The scalp topography depicts the location of the ERN (in blue).

Again, these results did not differ when using the frequency of T3 as an alternative avoidance measure (early acquisition: $\beta=$ $0.311 ; \mathrm{F}(1,51)=4.06, P=0.049, R^{2}=0.074$; late acquisition: $\beta$ $\left.=0.287 \mathrm{~F}(1,51)=2.08, P=0.156, R^{2}=0.039\right)$. When adding $\mathrm{CRN}$ and $\triangle \mathrm{ERN}$ as predictors, the multiple linear regression results remained significant for early acquisition $(F(2,50)=3.27, P$ $=0.046 ; R^{2}=0.116 ; \Delta \mathrm{ERN}$ excluded) and nonsignificant for late acquisition $\left(\mathrm{F}(2,50)=1.15, P=0.326 ; R^{2}=0.044 ; \Delta \mathrm{ERN}\right.$ excluded). During early acquisition, ERN but not $C R N$ was found to be a significant predictor of avoidance behavior $\left(\beta_{\text {ERN }}=0.009\right.$, $\left.P=0.014 ; \beta_{\mathrm{CRN}}=-0.007, P=0.189\right)$, whereas during late acquisition, both variables did not significantly predict avoidance $\left(\beta_{\mathrm{ERN}}=0.006, P=0.184 ; \beta_{\mathrm{CRN}}=-0.001, P=0.909\right)$. In all analyses, higher ERN amplitudes predicted less avoidance behavior during early acquisition.

\subsubsection{Error-related negativity and individual differences measures}

None of these measures correlated significantly with ERN or $\Delta$ ERN ( $r$ range $=-0.143$ to 0.073 , all $P>0.305$ ).

\section{Discussion}

The present study investigated the association between the ERN, a neural component of error processing, and pain-related avoidance in healthy individuals. According to the Holroyd and Coles model, ${ }^{24}$ the ERN signal "trains" the anterior cingulate cortex to improve its control over the motor system, eg, to "direct the motor system to avoid pain at all costs" (p. 685). Based on findings from anxiety research, we hypothesized individuals with larger ERN amplitudes to show more pronounced and persistent avoidance during a movement task with pain induction than individuals with smaller ERN amplitudes. Although pain expectancy and fear of movement-related pain to movement trajectories paired with painful stimulation were induced successfully and the expected patterns of avoidance behavior were observed, our results do not support the hypothesis that the ERN predicts painrelated behavioral avoidance in healthy individuals.

These results contrast with previous studies suggesting that the ERN indicates the evaluation of the relevance and motivational salience of errors ${ }^{1,70}$ and reflects individual sensitivity to endogenous threat, ${ }^{19}$ based on which defensive motivational systems are activated. ${ }^{20,24,68}$ The ERN was found to predict magnitudes of startle potentiation in healthy students on error commission $^{20}$ as well as the extent to which individuals learned from their mistakes rather than their correct responses. ${ }^{14}$ Weinberg et al. ${ }^{68}$ demonstrated that healthy adolescents with larger ERNs report more checking behaviors than their counterparts with smaller ERN amplitudes. Although previous research has not specifically focused on pain-related avoidance, studies on the relationship between ERN and avoidance behavior in general produced converging evidence in favor of such a relationship, supporting the theory by Holroyd and Coles $^{24}$ that the function of the ERN is to improve motor control.

However, the current results do not support this notion for the avoidance of acute experimental pain, for which there may be several explanations: First, it is possible that the ERN simply does not relate to pain-related avoidance behavior. An alternative explanation is that the present study differs greatly from previous research such that avoidance learning was (1) not measured in response to the task on which errors were committed nor by means of self-report and (2) it was assessed in a different session than the error task. Although it is unlikely that temporal proximity of measurements would have led to different results, given the demonstrated trait-like character of the $\mathrm{ERN},{ }^{52,67}$ it is plausible that the disjointedness between the 2 tasks could explain the absence of a relationship between ERN amplitude and avoidance behavior: Errors on the flanker task bore no relevance for the performance of the avoidance task. Participants who found error commission on the flanker task aversive and, subsequently, demonstrated elevated ERNs may not necessarily have found the commission of a bodily error, ie, painful movements on the HM task, aversive. Vice versa, pain-sensitive individuals and those holding negative beliefs about pain may have persistently avoided the painful movements despite showing little response to the pain-unrelated errors on the flanker task. Hence, large ERNs on the flanker task may reflect general sensitivity to errors, as could be the case in generalized anxiety disorder or obsessivecompulsive disorder, ${ }^{8,16,62,71}$ but not sensitivity to specific types of errors such as painful movements. A first study lending support to this hypothesis developed an interoceptive error commission paradigm, on which mistakes evoked an "interoceptive ERN", that was unrelated to its exteroceptive counterpart in response to the flanker task. ${ }^{60}$ Moreover, it can be speculated that flanker task errors have a more cognitive and less affective quality than painrelated prediction errors, which could imply the involvement of different cortical hierarchies. ${ }^{45} \mathrm{~A}$ third explanation for the present findings could be the use of a healthy student sample in which the variance in ERN amplitudes and avoidance might be smaller compared with a chronic pain sample, which renders it less likely to detect a potential correlation between the 2 variables. In particular, the healthy participants in this study might not have perceived the pain stimuli to be as salient and threatening as would persons with chronic pain. Finally, several psychosocial variables are known to influence avoidance, for instance, anxiety, ${ }^{31,53}$ intolerance of uncertainty, ${ }^{12}$ as well as the presence of competing goals ${ }^{3,63}$ or social threat, ${ }^{28}$ which could have moderated the postulated ERN-avoidance relationship, warranting further examination.

The unexpected finding of smaller ERN amplitudes predicting more avoidance at the start of acquisition was based on an exploratory analysis and therefore needs to be interpreted with caution. According to the computational model by Frank et al., ${ }^{14}$ persons with larger ERN amplitudes should be better at "learning to avoid maladaptive responses" (p. 495), which was supported by their experimental study. By contrast, our data seem to suggest that individuals with larger ERN amplitudes acquire avoidance behavior more slowly than persons with smaller ERNs. 
If this result can be replicated, it may bear clinically relevant implications: in the present experimental paradigm, contingencies were straightforward during acquisition, whereas in daily life, the occurrence and duration of pain are far less certain and predictable. Speculatively, persons with small ERNs may be more sensitive to these contingencies and more prone to engage in avoidance behavior. Consequently, it remains to be tested whether ERN amplitudes may specifically predict the early stages of avoidance learning.

The absence of correlations between ERN and any of the personality traits assessed is striking as several previous studies demonstrated associations of ERN amplitudes with anxiety, ${ }^{38,42}$ intolerance of uncertainty, ${ }^{26}$ and negative affect. ${ }^{22,33}$ A likely explanation for our null finding regarding intolerance of uncertainty is that we did not distinguish between prospective and inhibitory intolerance of uncertainty, which were both related to ERN in the study by Jackson et al., ${ }^{26}$ but in opposite directions. Because we could not disentangle the 2 factors in the current study, it is possible that their effects cancelled each other out. More remarkable is the finding that we did not replicate the widely reported association with anxiety. However, previously this relationship was mostly observed in clinical samples, ${ }^{39}$ whereas Meyer and Gawlowska ${ }^{38}$ found such association in healthy undergraduates only when the errors were punished, but not when error commission bore no consequences as was the case in the present study. These discrepancies signal a need for further research on the relationship between personality characteristics and ERN in healthy persons.

Some limitations of the present study need to be discussed. First, it cannot be ruled out that the absence of the hypothesized association between ERN and pain-related avoidance in the present study is the result of features of the experimental design: For methodological reasons, the 2 tasks used to measure ERN and avoidance were spatially and temporally separated, which might have made it more difficult to detect potentially small effects. Besides, the flanker task bore no relevance for pain in general and for the avoidance task specifically as a mistake on the former did not carry painful consequences and had no implications for performance on the arm reaching task. Future research should examine whether ERNs on a pain-relevant error commission task are associated with pain-related avoidance in general. The development of a novel paradigm to assess both error processing and avoidance in one task could provide further insights. ${ }^{61}$ Second, the HM task is considered to be a more ecologically valid measure of avoidance behavior than many other available tasks, among others due to the introduction of an avoidance cost. Yet this cost in the form of increased movement resistance was relatively low and the required effort was not rated as particularly high in the present study $(\mathrm{M}=4.0, \mathrm{SD}=1.8$; on a 10-point Likert scale). Thus, avoidance was not necessarily maladaptive and might therefore have reached a ceiling effect, which could have masked effects of individual differences. Third, the sample size calculation was based on the main analysis focusing on the acquisition of avoidance behavior such that the between-group analyses on LOP are likely underpowered. Given the importance of unpredictability in shaping the $E R N,{ }^{27,59}$ further research assessing its association with pain avoidance in unpredictable contexts is warranted. Fourth, the potential effects of relevant psychosocial variables on the relationship between ERN and avoidance were beyond the scope of this study but might have obscured a clear ERN-avoidance association. The role of these variables deserves closer attention in future investigations. Fifth, the generalizability of our results to individuals with chronic pain is limited as our sample consisted of young, healthy participants and because the occurrence of the experimental pain was likely too predictable to distinguish between individuals. Hence, future studies should use a partial reinforcement schedule to overcome the latter problem and extend to populations with chronic pain.

Taken together, the results of the present study indicate that pain-related avoidance in healthy individuals cannot be predicted based on their ERN amplitudes, although exploratory analyses suggest that early learning experiences may be shaped by individual differences in error processing. Although pain-related avoidance behavior has been gaining more scientific attention recently, the present research signifies an early step in mapping its underlying neural mechanisms. Given the arguable importance of avoidance behavior in maintaining chronic pain, studying these mechanisms is crucial to understand chronic pain and to inform clinical practice. Consequently, replications and extensions of this experiment are clearly warranted.

\section{Conflict of interest statement}

The authors have no conflicts of interest to declare.

\section{Acknowledgements}

The authors wish to thank all participants for their time, Mathijs Franssen for his technical support in programming the experiment and conducting the analyses, and the reviewers for their constructive feedback. This work was supported by the "Asthenes" long-term structural funding Methusalem grant (METH/15/011) from the Flemish Government, Belgium, and by an infrastructure grant from the Research Foundation Flanders (FWO), Belgium, and the Research Fund KU Leuven, Belgium (AKUL/19/06; I011320N). All authors contributed and approved the final version submitted.

Parts of the data have been presented in abstract form at the IASP World Congress on Pain 2018 in Boston, MA, and at the IASP World Congress on Pain Virtual Event 2020.

\section{Article history:}

Received 12 January 2021

Received in revised form 12 April 2021

Accepted 14 April 2021

Available online 1 june 2021

\section{References}

[1] Aarts K, Pourtois G. Anxiety not only increases, but also alters early errormonitoring functions. Cogn Affect Behav Neurosci 2010;10:479-92.

[2] Arntz A, Van Eck M, de Jong P. Avoidance of pain of unpredictable intensity. Behav Res Ther 1991;29:197-201.

[3] Claes N, Karos K, Meulders A, Crombez G, Vlaeyen JWS. Competing goals attenuate avoidance behavior in the context of pain. J Pain 2014;15: 1120-9.

[4] Crawford JR, Henry JD. The Positive and Negative Affect Schedule (PANAS): construct validity, measurement properties and normative data in a large non-clinical sample. Br J Clin Psychol 2004;43:245-65.

[5] de Bruin GO, Rassin E, van der Heiden C, Muris P. Psychometric properties of a Dutch version of the intolerance of uncertainty scale. Neth J Psychol 2006;62:87-92.

[6] Di Gregorio F, Maier ME, Steinhauser M. Errors can elicit an error positivity in the absence of an error negativity: evidence for independent systems of human error monitoring. Neurolmage 2018;172:427-36.

[7] Dutilh G, van Ravenzwaaij D, Nieuwenhuis S, van der Maas HL, Forstmann BU, Wagenmakers EJ. How to measure post-error slowing: a confound and a simple solution. J Math Psycho 2012;56:208-16.

[8] Endrass T, Schuermann B, Kaufmann C, Spielberg R, Kniesche R, Kathmann N. Performance monitoring and error significance in patients with obsessive-compulsive disorder. Biol Psychol 2010;84:257-63. 
[9] Eriksen BA, Eriksen CW. Effects of noise letters upon the identification of a target letter in a nonsearch task. Percept Psychophys 1974;16:143-9.

[10] Faul F, Erdfelder E, Buchner A, Lang AG. Statistical power analyses using $G^{\star}$ Power 3.1: tests for correlation and regression analyses. Behav Res Methods 2009;41:1149-60.

[11] Faul F, Erdfelder E, Lang AG, Buchner A. G* Power 3: a flexible statistical power analysis program for the social, behavioral, and biomedical sciences. Behav Res Methods 2007;39:175-91.

[12] Flores A, López FJ, Vervliet B, Cobos PL. Intolerance of uncertainty as a vulnerability factor for excessive and inflexible avoidance behavior. Behav Res Ther 2018;104:34-43.

[13] Forster B, Pavone EF. Electrophysiological correlates of crossmodal visual distractor congruency effects: evidence for response conflict. Cogn Affect Behav Neurosci 2008;8:65-73.

[14] Frank MJ, Woroch BS, Curran T. Error-related negativity predicts reinforcement learning and conflict biases. Neuron 2005;47:495-501.

[15] Freeston MH, Rhéaume J, Letarte H, Dugas MJ, Ladouceur R. Why do people worry?. Pers Individ Dif 1994;17:791-802.

[16] Gehring WJ, Himle J, Nisenson LG. Action-monitoring dysfunction in obsessive-compulsive disorder. Psychol Sci 2000;11:1-6.

[17] Glaesmer H, Rief W, Martin A, Mewes R, Brähler E, Zenger M, Hinz A. Psychometric properties and population-based norms of the life orientation test revised (LOT-R). Br J Health Psychol 2012;17:432-45.

[18] Glogan E, Gatzounis R, Meulders M, Meulders A. Generalization of instrumentally acquired pain-related avoidance to novel but similar movements using a robotic arm-reaching paradigm. Behav Res Ther 2020;124:103525.

[19] Hajcak G. What we've learned from mistakes: insights from error-related brain activity. Curr Dir Psychol Sci 2012;21:101-6.

[20] Hajcak G, Foti D. Errors are aversive: defensive motivation and the errorrelated negativity. Psychol Sci 2008;19:103-8.

[21] Hajcak G, Klawohn J, Meyer A. The utility of event-related potentials in clinical psychology. Annu Rev Clin Psychol 2019;15:71-95.

[22] Hajcak G, McDonald N, Simons RF. Error-related psychophysiology and negative affect. Brain Cogn 2004;56:189-97.

[23] Helsen K, Van den Bussche E, Vlaeyen JW, Goubert L. Confirmatory factor analysis of the Dutch Intolerance of Uncertainty Scale: comparison of the full and short version. Behav Ther Exp Psychiatry 2013;44:21-9.

[24] Holroyd CB, Coles MG. The neural basis of human error processing: reinforcement learning, dopamine, and the error-related negativity. Psychol Rev 2002;109:679.

[25] IBM Corp. Released 2017. IBM SPSS Statistics for Windows. Armonk, NY: IBM Corp.

[26] Jackson F, Nelson BD, Hajcak G. The uncertainty of errors: intolerance of uncertainty is associated with error-related brain activity. Biol Psychol 2016;113:52-8

[27] Jackson F, Nelson BD, Proudfit GH. In an uncertain world, errors are more aversive: evidence from the error-related negativity. Emotion 2015;15:12.

[28] Karos K, Meulders A, Vlaeyen JW. Threatening social context facilitates pain-related fear learning. J Pain 2015;16:214-25.

[29] Karsdorp PA, Vlaeyen JW. Goals matter: both achievement and painavoidance goals are associated with pain severity and disability in patients with low back and upper extremity pain. PAIN 2011;152:1382-90.

[30] Keil A, Debener S, Gratton G, Junghöfer M, Kappenman ES, Luck SJ, Luu P, Miller GA, Yee CM. Committee report: publication guidelines and recommendations for studies using electroencephalography and magnetoencephalography. Psychophysiology 2014;51:1-21.

[31] Klein Z, Shner G, Ginat-Frolich R, Vervliet B, Shechner T. The effects of age and trait anxiety on avoidance learning and its generalization. Behav Res Ther 2020;129:103611.

[32] Lamé IE, Peters ML, Kessels AG, Van Kleef M, Patijn J. Test-retest stability of the pain catastrophizing scale and the tampa scale for kinesiophobia in chronic pain over a longer period of time. J Health Psychol 2008;13:820-6.

[33] Luu P, Collins P, Tucker DM. Mood, personality, and self-monitoring: negative affect and emotionality in relation to frontal lobe mechanisms of error monitoring. J Exp Psychol Gen 2000;129:43.

[34] Markfelder T, Pauli P. Fear of pain and pain intensity: meta-analysis and systematic review. Psychol Bull 2020;146:411.

[35] Martinez-Calderon J, Flores-Cortes M, Morales-Asencio JM, LuqueSuarez A. Pain-related fear, pain intensity and function in individuals with chronic musculoskeletal pain: a systematic review and meta-analysis. J Pain 2019;20:1394-415.

[36] Meulders A, Franssen M, Fonteyne R, Vlaeyen JWS. Acquisition and extinction of operant pain-related avoidance behavior using a 3 degreesof-freedom robotic arm. PAIN 2016;157:1094-104.
[37] Meulders A, Vlaeyen JW. The acquisition and generalization of cued and contextual pain-related fear: an experimental study using a voluntary movement paradigm. PAIN 2013;154:272-82.

[38] Meyer A, Gawlowska M. Evidence for specificity of the impact of punishment on error-related brain activity in high versus low trait anxious individuals. Int J Psychophysiol 2017;120:157-63.

[39] Miltner WH, Braun CH, Coles MG. Event-related brain potentials following incorrect feedback in a time-estimation task: evidence for a "generic" neural system for error detection. J Cogn Neurosci 1997;9:788-98.

[40] Miltner WH, Lemke U, Weiss T, Holroyd C, Scheffers MK, Coles MG. Implementation of error-processing in the human anterior cingulate cortex: a source analysis of the magnetic equivalent of the error-related negativity. Biol Psychol 2003;64:157-66.

[41] Moser JS, Hajcak G, Simons RF. The effects of fear on performance monitoring and attentional allocation. Psychophysiology 2005;42:261-8.

[42] Olvet DM, Hajcak G. The error-related negativity (ERN) and psychopathology: toward an endophenotype. Clin Psychol Rev 2008; 28:1343-54.

[43] Olvet DM, Hajcak G. Reliability of error-related brain activity. Brain Res 2009;1284:89-99.

[44] Olvet DM, Hajcak G. The stability of error-related brain activity with increasing trials. Psychophysiology 2009;46:957-61.

[45] Ploner M, Sorg C, Gross J. Brain rhythms of pain. Trends Cogn Sci 2017; 21:100-10.

[46] Rabbitt P. Errors and error correction in choice-response tasks. Jo J Exp Psychol 1966;71:264.

[47] Riesel A. The erring brain: error-related negativity as an endophenotype for OCD—a review and meta-analysis. Psychophysiology 2019;56: e13348.

[48] Riesel A, Klawohn J, Grützmann R, Kaufmann C, Heinzel S, Bey K, Lennertz L, Wagner M, Kathmann N. Error-related brain activity as a transdiagnostic endophenotype for obsessive-compulsive disorder, anxiety and substance use disorder. Psychol Med 2019;49:1207-17.

[49] Riesel A, Weinberg A, Endrass T, Meyer A, Hajcak G. The ERN is the ERN is the ERN? Convergent validity of error-related brain activity across different tasks. Biol Psychol 2013;93:377-85.

[50] Sandre A, Banica I, Riesel A, Flake J, Klawohn J, Weinberg A. Comparing the effects of different methodological decisions on the error-related negativity and its association with behaviour and gender. Int J Psychophysiol 2020;156:18-39.

[51] Scheier MF, Carver CS, Bridges MW. Distinguishing optimism from neuroticism (and trait anxiety, self-mastery, and self-esteem): a reevaluation of the Life Orientation Test. J Pers Soc Psychol 1994;67: 1063.

[52] Segalowitz SJ, Santesso DL, Murphy TI, Homan D, Chantziantoniou DK, Khan S. Retest reliability of medial frontal negativities during performance monitoring. Psychophysiology 2010;47:260-70

[53] Sege CT, Bradley MM, Lang PJ. Avoidance and escape: defensive reactivity and trait anxiety. Behav Res Ther 2018;104:62-8.

[54] Spielberger C, Gorsuch R, Lushene R, Vagg P, Jacobs G. Manual for the state-trait anxiety inventory. Palo Alto: Consulting Psychologists Press. Inc, 1983.

[55] Spielberger C, Gorsuch R, Lushene R, Vagg P, Jacobs G. State-Trait Anxiety Inventory for Adults: Sampler set: Manual. Test, Scoring Key. Palo Alto, CA: Consulting Psychologists Press, 1983.

[56] Spruyt A, Clarysse J, Vansteenwegen D, Baeyens F, Hermans D. Affect 4.0: a free software package for implementing psychological and psychophysiological experiments. Exp Psychol 2009;57:36-45.

[57] Sucec J, Herzog M, Van Diest I, Van den Bergh O, von Leupoldt A. The impact of dyspnea and threat of dyspnea on error processing. Psychophysiology 2019;56:e13278.

[58] Sullivan MJ, Bishop SR, Pivik J. The pain catastrophizing scale: development and validation. Psychol Assess 1995;7:524

[59] Tan Y, Van den Bergh O, Qiu J, Von Leupoldt A. The impact of unpredictability on dyspnea perception, anxiety and interoceptive error processing. Front Physiol 2019;10:535.

[60] Tan Y, Vandeput J, Qiu J, Van den Bergh O, von Leupoldt A. The errorrelated negativity for error processing in interoception. Neurolmage 2019; 184:386-95

[61] Traxler J, Philips RV, von Leupoldt A, Vlaeyen JW. Trial and error (-related negativity): an odyssey of integrating different experimental paradigms. JOTE 2020;1:27-38.

[62] Ursu S, Stenger VA, Shear MK, Jones MR, Carter CS. Overactive action monitoring in obsessive-compulsive disorder: evidence from functional magnetic resonance imaging. Psychol Sci 2003;14:347-53.

[63] Van Damme S, Van Ryckeghem DML, Wyffels F, Van Hulle L, Crombez G. No pain no gain? Pursuing a competing goal inhibits avoidance behavior. PAIN 2012;153:800-4. 
[64] Vlaeyen JW, Crombez G, Linton SJ. The fear-avoidance model of pain. PAIN 2016;157:1588-9.

[65] Vlaeyen JW, Linton SJ. Fear-avoidance and its consequences in chronic musculoskeletal pain: a state of the art. PAIN 2000;85:317-32.

[66] Watson D, Clark LA, Tellegen A. Development and validation of brief measures of positive and negative affect: the PANAS scales. J Pers Soc Psychol 1988;54:1063.

[67] Weinberg A, Hajcak G. Longer term test-retest reliability of error-related brain activity. Psychophysiology 2011;48:1420-5.

[68] Weinberg A, Meyer A, Hale-Rude E, Perlman G, Kotov R, Klein DN, Hajcak G. Error-related negativity (ERN) and sustained threat: conceptual framework and empirical evaluation in an adolescent sample. Psychophysiology 2016;53:372-85.

[69] Weinberg A, Olvet DM, Hajcak G. Increased error-related brain activity in generalized anxiety disorder. Biol Psychol 2010;85:472-80.
[70] Weinberg A, Riesel A, Hajcak G. Integrating multiple perspectives on error-related brain activity: the ERN as a neural indicator of trait defensive reactivity. Motiv Emot 2012;36:84-100.

[71] Xiao Z, Wang J, Zhang M, Li H, Tang Y, Wang Y, Fan Q, Fromson JA. Error-related negativity abnormalities in generalized anxiety disorder and obsessive-compulsive disorder. Prog Neuropsychopharmacol Biol Psychiatry 2011;35:265-72.

[72] Yasuda A, Sato A, Miyawaki K, Kumano H, Kuboki T. Error-related negativity reflects detection of negative reward prediction error. Neuroreport 2004;15:2561-5.

[73] Zale EL, Lange KL, Fields SA, Ditre JW. The relation between pain-related fear and disability: a meta-analysis. J Pain 2013;14:1019-30.

[74] Zambrano-Vazquez L, Allen JJ. Differential contributions of worry, anxiety, and obsessive compulsive symptoms to ERN amplitudes in response monitoring and reinforcement learning tasks. Neuropsychologia 2014;61: 197-209. 